\title{
A Cobrança de Taxa como Alternativa de Financiamento para um Plano de Drenagem Urbana no Município de Belém/PA
}

\author{
Érico Gaspar Lisbôa; Ana Rosa Baganha Barp; André A. A Montenegro Duarte \\ Programa de Pós-graduação em Engenharia Civil/UFPA \\ erico@ufpa.br; anabarp@ufpa.br; amonte@ufpa.br
}

Recebido: 23/08/09 - revisado: 31/08/10 - aceito: 10/05/12

\section{RESUMO}

As ações públicas municipais em sistemas de drenagem urbana, na maioria das cidades brasileiras, demandam significativos investimentos. Tais investimentos advêm de recursos estatais, da união e/ou de fundos internacionais, e são destinadas as ações estruturais e não estruturais para implementação e manutenção de um plano de drenagem. Por outro lado, estas ações fazem por onerar a máquina administrativa municipal, enfraquecendo, sobremaneira, as medidas preventivas (não estruturais) e fortalecendo medidas corretivas (estruturais) as quais esbarram na incompatibilidade orçamentária do município perpetuando a cultura do empréstimo. O presente artigo aborda como objetivo principal a valoração de uma taxa em uma Área Experimental de Cobrança (AEC) no município de Belém/PA possibilitando a obtenção de parâmetros para inferir sobre a viabilidade de financiamento do setor de drenagem urbana. A área de análise está localizada no bairro da Terra Firme, inserida na bacia hidrográfica do Tucunduba, que no ano de 2002 recebeu um investimento de $R \$ 9,88$ milhões na $1^{\underline{a}}$ das 3 etapas do projeto contemplando um plano de drenagem, de micro e macrodrenagem. Deste montante, $73 \%$ foram originados de um empréstimo junto ao FGTS e $27 \%$ financiada pelo próprio município. Os dados estimados para AEC apresentaram em média 4,16 habitantes/domicílios, referentes a uma área de 48.415, $74 \mathrm{~m}^{2}$, donde 78,21\% são ocupadas de forma desordenada e 59,24\% destas ocupações representam áreas impermeabilizadas; já que a característica econômica da população, no que concerne a renda, é cerca de 2 salários mínimos. Assim, preliminarmente, evidenciou-se o aspecto histórico das obras drenagem no município de Belém/PA, bem como a fundamentação acerca do Plano Diretor Urbano e das formas de financiamento da drenagem urbana, as quais dão aporte para o entendimento das questões legais da cobrança. Aplicou-se os métodos de Tucci (2002) e Gomes et. al (2008) cujos resultados foram correlacionados com a área e testada do imóvel; e renda familiar para cada unidade residencial, obtendo-se modelos exequíveis conforme coeficiente de determinação. Estes modelos apresentam-se como mecanismo de financiamento da drenagem urbana para o município de Belém/PA podendo ser aplicados para outras áreas conforme o zoneamento municipal.

Palavra-Chave: Plano de Drenagem Urbana, Taxa, bacia do Tucunduba, município de Belém/PA.

\section{INTRODUÇÃOO}

Os investimentos públicos em infraestrutura para o planejamento dos recursos hídricos são de difícil estimativa, pois a alocação desses recursos orçamentários é dispersa entre diversos ministérios e governos estaduais (Margulis et. al, 2002).

Dados parciais do estudo de Margulis et al., (2002), para financiar ações de saneamento, recursos hídricos e meio ambiente no Brasil, sugeriu que a média anual de investimentos superou os $\mathrm{R} \$ 5$ bilhões, enquanto o volume "necessário" de novos investimentos no setor hídrico, nos próximos 5 a 10 anos, deve começar em cerca de, $\mathrm{R} \$ 20$ bilhões, podendo chegar a muito mais.
Tucci (2005), por sua vez, apresentou a necessidade de investimento para um programa nacional de águas pluviais que controlasse os impactos na drenagem e inundação das cidades, e identificou um total de $\mathbf{R} \$ 21,5$ bilhões em 24 anos para solução desses impactos, representando até $0,2 \%$ do PIB anual.

Tucci (2005) afirmou, novamente, com base nas estimativas anteriores, ser possível antever a necessidade de investimentos da ordem de $0,8 \%$ do PIB para o saneamento ambiental (sem incluir resíduos sólidos). Para este autor, esse percentual representaria cerca de $R \$ 16$ bilhões por ano em água, esgoto e drenagem para, no horizonte de aproximadamente 20 anos, constituírem um processo sustentável de desenvolvimento urbano 
Tais afirmações são deveras constatadas pelas ações públicas na gestão dos recursos hídricos, mais precisamente no setor de drenagem urbana na cidade de Belém/PA. O marco destes empreendimentos no município, segundo Portela (2004), com a criação do Departamento Nacional de Obras e Saneamento (DNOS) em 1974, foi à construção de canais na bacia do Tamandaré.

O objetivo desse empreendimento foi mitigar as enchentes em períodos de cheia, e ainda abranger obras de saneamento do canal das Almas, situadas atualmente na bacia hidrográfica do Reduto. Trindade Jr (1997) revelou a necessidade de intervir no conjunto que formava as bacias hidrográficas, exigindo a assinatura de um convênio, em 1976, entre o DNOS, a Superintendência de Desenvolvimento da Amazônia (SUDAM), o governo do Estado e a Prefeitura Municipal de Belém (PMB).

Institui-se, desse modo, o Programa de Recuperação das Baixadas (PRB), que tomou duas direções complementares: uma compreendeu o Plano Global e a outra o Plano de Ação Imediata (PAI). Este último seria uma experiência piloto de orientação para outras obras de drenagem urbana.

Assim, com iniciativa da PMB, em 1986 nascia à concepção do Projeto de Macrodrenagem da bacia do Una, que segundo Portela (2004), consistiu na abertura e retificação dos igarapés com o fim de eliminar o alagamento, dotando-os de infraestrutura, saneamento básico e sistema viário. O financiamento para a realização dos serviços, da ordem de US\$ 85 bilhões, foi do Banco Interamericano de Desenvolvimento (BID) e do governo do estado do Pará.

Não obstante, em meados de 1997, com intensa participação da sociedade civil, elaborou-se o projeto de macrodrenagem da bacia do igarapé Tucunduba que fora constituído de três etapas, sendo que a $1^{\underline{a}}$ fase foi concluída em 2004. Foi empenhado, segundo o SNAI (2004), pela PMB um empréstimo junto ao FGTS de $\mathrm{R} \$ 9,88$ milhões, sendo $73 \%$ de financiamento e $27 \%$ contrapartida da PMB, objetivando a recuperação do canal do Tucunduba.

Neste sentido, qual alternativa poderia ser utilizada para autossustentação financeira da drenagem urbana do município de Belém/PA?

Assim, a proposição deste artigo é aferir o método Tucci (2002) e Gomes et al. (2008) para quantificar taxas de drenagem. Os valores de taxa são correlacionados com parâmetros dos imóveis (área construída e testada) e renda familiar por unidade residencial em uma Área Experimental de Cobrança (AEC) localizada na bacia do Tucunduba no município de Belém/PA. Tais correlações possibilitam a extrapolação de modelos que melhor se ajustem ao zoneamento de uso do solo do município, fundamentando a gestão financeira dos sistemas de drenagem urbana.

Para tanto, faz-se uma breve caracterização histórica das obras de drenagem da cidade de Belém, bem como a fundamentação acerca do Plano Diretor Urbano (PDU) e das formas de financiamento da drenagem urbana, as quais dão aporte para o entendimento das questões legais da cobrança. Não obstante, realiza-se a caracterização da região onde se insere a AEC, e, por conseguinte aplicam-se os métodos supracitados e, por fim, obtem-se os resultados.

\section{CONTEXTO LOCAL E FUNDAMENTAÇÃ̃O TEÓRICA}

As ações públicas na gestão dos recursos hídricos, especificamente no setor de drenagem urbana na cidade de Belém/PA, são contextualizadas no Plano Diretor Urbano (PDU). Neste contexto, fundamentam-se as formas de financiamento da drenagem urbana, as quais dão suporte ao entendimento das questões legais da cobrança.

\section{Plano Diretor Urbano de Belém/PA}

O Plano Diretor de Drenagem, segundo Tucci (1997), devem ter como meta:

a) Planejar a distribuição da água no tempo e no espaço, com base na tendência de ocupação urbana compatibilizando esse desenvolvimento e a infraestrutura para evitar prejuízos econômicos e ambientais;

b) Controlar a ocupação de áreas de risco de inundação através de restrições nas áreas de alto risco, e;

c) Convivência com as enchentes nas áreas de alto risco.

Neste sentido, a política de infraestrutura e meio ambiente do PDU em Belém prevê a integração dos setores e diretrizes para a concepção da Política Municipal de Saneamento Ambiental Integrado. Tais diretrizes legais devem, a priori, ser fon- 
tes de reflexão do gestor público, e, depois de compreendida, de fato ser executada.

No que concerne a execução das intervenções e estruturas de regulamentação, o próprio PDU é atrelado aos governos estaduais e federais devendo se articular para efetivar as medidas necessárias. Assim, o meio de planejar é integrado, mas, para que este seja efetivado, a forma ainda é centralizada. Neste sentido, a fragilidade financeira municipal para gerenciar a problemática da drenagem urbana, ainda é incipiente.

Assim, adota-se uma postura assistencialista contornada por empréstimos financeiros, catalisando o aumento da dívida pública, a precariedade dos serviços, o sucateamento das estruturas existentes e acréscimo de novas problemáticas, tornando esta uma política viciosa.

Portanto, os custos empenhados pelo gestor público para financiar ações estruturais e não estruturais nas bacias do Una e Tucunduba não tiveram o retorno esperado, cujo ônus se eleva por alagamentos, e outros problemas de ordem social. Neste sentido, urgem meios de financiamento com ações direcionadas ao financiamento da drenagem urbana municipal.

\section{Financiamento da drenagem urbana}

As gestões públicas, relativo ao financiamento de obras de drenagem, dispõem de algumas alternativas de captação dos recursos como a cobrança pela prestação de serviços à comunidade, o planejamento financeiro e a alocação de recursos do IPTU.

Destacam-se na literatura, dentre outras, três contribuições importantes. A primeira evidencia o que fora realizado na Inglaterra, segundo Barraqué (1995), por meio de taxas embutidas na cobrança da água, em função do valor do imóvel e do consumo efetiva de águas.

Já a segunda, vista no Brasil, São Paulo, Marcon (1999) aponta que uma das alternativas foi à cobrança de taxas em função das áreas coberta dos imóveis. E, por fim, a terceira, Antener (1999) revelou o que acontece em Zurique, na Suíça, onde a cobrança se fundamenta por meio da área impermeabilizada dos imóveis.

O trabalho realizado na área experimental de cobrança, adotando os métodos descritos no item 4 , as formas de implementação das taxas de drenagem, salvaguardando algumas limitações, não diferem das experiências supracitadas.

\section{Questões legais da cobrança}

Baptista e Nascimento (2002), afirmaram que, a cobrança de taxas para os serviços de drenagem urbana é complexa pela indivisibilidade da oferta e do uso, posto que os sistemas hidráulicos de infraestrutura urbana são caracterizados como bens e serviços de caráter público.

No entanto, a outorga como mecanismo de gestão e planejamento dos recursos hídricos, ganha sustentação legal com a Lei Federal nº 9.433/97. Assim, é permitida a cobrança pelo uso dos recursos hídricos conforme o Art. 19º, inciso III, especificamente. Na referida ordem, que analisa o Art. $77^{\circ}$ da qual figura sobre a implementação de taxas, é imperioso observar que esta prática se faz presente, em grande maioria dos serviços públicos demandados pela população, não vinculado obrigatoriamente de seu uso efetivo como visto pelo Art. 79.

No que concerne a cobrança dos serviços de drenagem a partir de uma taxa, apóia-se na Lei $\mathrm{n}^{\text {o }}$ 5.172/66 que dispõe sobre a tributação nacional, estadual e municipal. De acordo com Gomes et al. (2008), a taxa de drenagem, referenciada à área impermeabilizada dos imóveis (genericamente, novos ou existentes), encontra embasamento técnico, político e legal (Lei no 9.433/97), o que poderá facilitar a sua viabilidade.

\section{ÁREA EXPERIMENTAL DE COBRANÇA (AEC)}

A bacia do Tucunduba (11) faz parte do conjunto de 13 bacias que integram o município de Belém. Com área de $10,55 \mathrm{~km}^{2}$, localizada a sudeste de Belém, tem o igarapé Tucunduba como principal curso d'água com $3,6 \mathrm{~km}$ de extensão sendo um afluente do Rio Guamá (SNAI, 2004).

Nesta bacia localiza-se a área onde a pesquisa foi desenvolvida, isto é, a AEC, com 48,42 km², donde $78,21 \%$ são ocupadas de forma desordenada e 59,24\% impermeabilizadas (SNAI, 2004). Esta área foi constituída de um Plano de Desenvolvimento Local (PDL) do Riacho Doce e Pantanal, áreas de ocupação de um dos bairros mais populosos de Belém, como parte integrante do plano de drenagem do igarapé Tucunduba. (Fig. 1).

O plano, nesta região, contemplou projetos de macro e microdrenagem (Tab. 1) retificando $1,080 \mathrm{~km}$ de canal. Na execução do PDL, R \$ 1,65 milhões foram assegurados pelo município e o restante, $\mathrm{R} \$ 10,89$ milhões. 


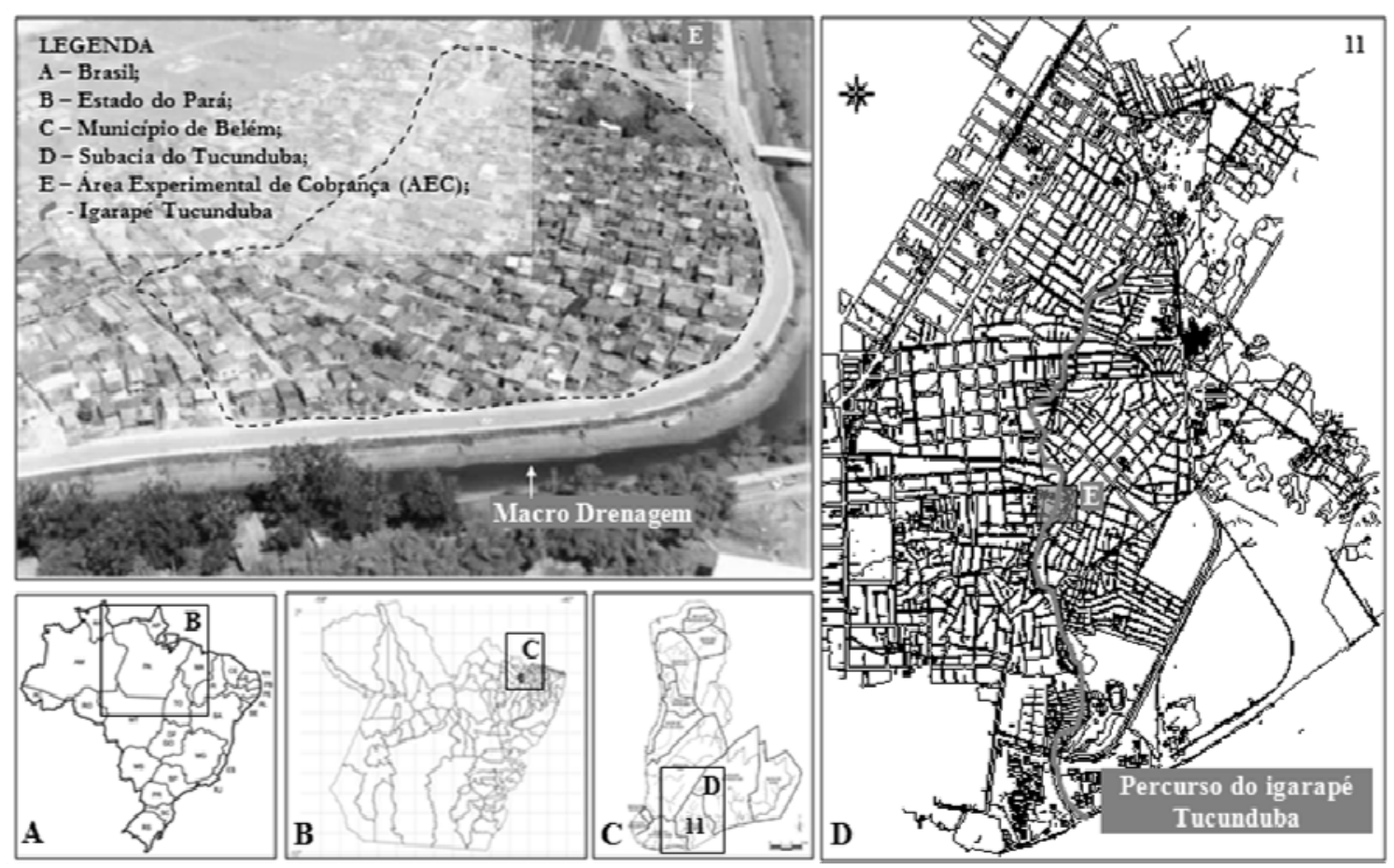

Figura 1 - Mapa da AEC: A) Brasil; B) Estado do Pará; C) Bacias de Belém e D) Subbacia do Tucunduba.

Tabela 1 - Valores da obra de drenagem da subbacia 11.

\begin{tabular}{|c|c|c|c|c|}
\hline \multicolumn{5}{|c|}{ Macrodrenagem (I) } \\
\hline \multicolumn{3}{|l|}{ Item } & \multicolumn{2}{|c|}{ Valor $(\mathbf{R} \$)$} \\
\hline \multicolumn{3}{|c|}{ Serviços Preliminares } & \multicolumn{2}{|c|}{$100.547,64$} \\
\hline \multicolumn{3}{|l|}{ Canal } & \multicolumn{2}{|c|}{$2.640 .086,96$} \\
\hline \multicolumn{3}{|l|}{ Vias Marginais } & \multicolumn{2}{|c|}{$2.661 .808,92$} \\
\hline \multicolumn{3}{|l|}{ Pontes } & \multicolumn{2}{|c|}{$668.363,26$} \\
\hline \multicolumn{3}{|l|}{ Passarelas } & \multicolumn{2}{|c|}{$93.324,50$} \\
\hline \multicolumn{3}{|c|}{ Drenagem Pluvial } & \multicolumn{2}{|c|}{$1.160 .514,96$} \\
\hline \multicolumn{3}{|c|}{ Desapropriações } & \multicolumn{2}{|c|}{$2.658 .909,50$} \\
\hline \multicolumn{3}{|l|}{ Projetos } & \multicolumn{2}{|c|}{$148.230,00$} \\
\hline \multicolumn{3}{|l|}{ Subtotal (I) } & \multicolumn{2}{|c|}{$10.131 .785,74$} \\
\hline \multicolumn{3}{|c|}{$\begin{array}{l}\text { Custo de } \\
\text { Implementação }(R \$ / m)\end{array}$} & \multicolumn{2}{|c|}{$9.381,28$} \\
\hline Custo de Manu & enção $(R \$$ & & 550 & \\
\hline Microdrenage & n (II) & & & \\
\hline $\begin{array}{l}\text { Diâmetro - } \\
\text { D (mm) }\end{array}$ & $\begin{array}{l}\text { Comp. } \\
\text { (m) }\end{array}$ & \multicolumn{2}{|c|}{$(\mathbf{R} \$ / \mathbf{m})$} & Custo $(\mathbf{R} \$)$ \\
\hline 400 & $2.897,0$ & \multicolumn{2}{|c|}{26,79} & $77.610,63$ \\
\hline 600 & 60,0 & \multicolumn{2}{|c|}{54,16} & $3.249,60$ \\
\hline 800 & 40,0 & \multicolumn{2}{|c|}{79,36} & $3.174,40$ \\
\hline 1000 & 696,0 & \multicolumn{2}{|c|}{106,94} & $74.430,24$ \\
\hline Subtotal (II) & $3.693,0$ & \multicolumn{2}{|c|}{294,04} & $1.085 .889,72$ \\
\hline \multicolumn{4}{|l|}{ TOTAL } & $11.217 .675,46$ \\
\hline
\end{tabular}

Estas cifras foram adquiridas por empréstimo ao programa habitar Brasil do BID, captados junto à secretaria especial de desenvolvimento urbano da presidência da república, na ação melhoria das condições habitacionais de infraestrutura e de saneamento básico (SNAI, 2004). Esta fase do projeto contemplou ações de saneamento, pavimentação, reordenamento urbano, dentre outros, sendo beneficiadas 1.537 famílias.

Os custos do sistema de drenagem somaram $\mathrm{R} \$ 11,22$ milhões, conforme os dados do projeto básico fornecidos pela Secretaria de Saneamento de Belém (SESAN), responsável pela fiscalização do empreendimento. No entanto, SNAI (2004) esclareceu que os recursos alocados somavam $\mathrm{R} \$ 12,54$ milhões, sendo que tais diferenças são justificadas por alterações do projeto ao longo de sua execução dentre outros ajustes.

Portanto, a aplicação da metodologia adotada, descritas a seguir, para a quantificação das taxas de drenagem tiveram suporte nos custos de implementação e manutenção dos sistemas de drenagem (adotando uma estimativa em torno de 5\% do custo de implementação) já efetivados pelo gestor municipal visto pela Tabela 1 .

Fonte: SESAN, 2002 


\section{METODOLOGIA ADOTADA}

No presente artigo utilizaram-se, para quantificar a taxa de drenagem, dois processos. O primeiro evidencia o rateio dos custos diretos, que incide o ônus da implementação das obras de um plano de drenagem; e os indiretos, abrangendo os custos de operação e manutenção dos sistemas de drenagem. O segundo não é incidente sobre o índice de impermeabilização da bacia; mas, é pertinente sobre os custos do sistema de drenagem, a contribuição de cada lote e das vias públicas, sejam estes urbanizados ou não. Assim, delimitada AEC, inferese as metodologias descritas abaixo, salvaguardando limitações e adaptações.

\section{Método de Tucci (2002)}

O método de cálculo proposto por Tucci (2002) evidencia dois aspectos principais: o rateio dos custos indiretos, abrangendo os custos de operação e manutenção dos sistemas de drenagem; e os diretos, incide o ônus da implementação das obras de um plano de drenagem.

Rateio dos custos indiretos - $T x_{\text {indiretos }}$

Para calcular as taxas provenientes dos custos de manutenção e operação de um sistema de drenagem, reflexos de ações preventivas, tem-se:

$\mathrm{T}_{\mathrm{x}_{\text {indireto }}}=\frac{\text { A. }_{\mathrm{u}_{\mathrm{i}}}}{100} \cdot\left(28,43+0,623 \cdot \mathrm{i}_{1}\right)$

Onde $\mathrm{Tx}_{\text {indiretos }}$ é a taxa anual a ser cobrada, pelo imóvel de área $\mathrm{A}\left(\mathrm{m}^{2}\right)$, em $\mathrm{R} \$$; A é a área do imóvel $\left(\mathrm{m}^{2}\right)$; $\mathrm{i}_{1}$ é o percentual de área impermeabilizada do imóvel; $\mathrm{Cu}_{\mathrm{i}}$ é o custo unitário das áreas impermeáveis $\left(\mathrm{R} \$ / \mathrm{m}^{2}\right)$.

A obtenção de $\mathrm{Tx}_{\text {indiretos }}$ foi precedida de adaptações pertinentes a área delimitada nesta pesquisa, a qual está inserida na bacia do Tucunduba. Assim, o valor de A fora igualmente tratada como a área de cada terreno $\left(\mathrm{A}_{\text {terreno }}\right)$ do loteamento aqui estudado.

O valor de $i_{1}$ fora obtida através da relação de área construída $\left(\mathrm{A}_{\text {const }}\right)$ pela $\mathrm{A}_{\text {terreno. Não obstante, }}$. tais adequações na mensuração de $\mathrm{A}_{\text {const }}$, na localidade experimentada, realizado pela $\mathrm{PMB}$, originaram um banco de dados compilando $\mathrm{A}_{\text {const }}>\mathrm{A}_{\text {terreno, }}$, denotando que em um lote sua área impermeável é maior que o próprio terreno.
Neste sentido, no processo utilizado no trabalho em pauta, para quantificar áreas impermeáveis para o caso acima descrito, utilizou-se o que preceitua a NBR-12721, que regula sobre a avaliação de custos unitários e preparo de orçamento de construção para incorporação de edifícios. Deste modo, calcula-se a área equivalente de construção $(S)$. Este procedimento é utilizado para que o cálculo do custo unitário básico adotado tenha o mesmo custo, que o efetivamente estimado para área real correspondente, descoberta ou coberta de padrão diferente.

Dantas (2003) citou um exemplo na incorporação de um condomínio, onde a razão entre a área equivalente de construção da unidade residencial e área equivalente total fornece a fração ideal correspondente à unidade. Esta fração ideal multiplicada pela área do terreno fornece a quota parte de terreno pertencente à unidade. De tal modo que para se determinar a parte impermeável do terreno, no caso em questão, têm-se a formulação abaixo:

$\mathrm{S}=\mathrm{A} \cdot \mathrm{P}+\mathrm{A}_{\mathrm{q}} \cdot \mathrm{P}$

Sendo A é a área construída padrão obtida pela razão entre o custo estimado da área de padrão diferente e o custo estimado de área padrão. $\mathrm{O}$ valor de $\mathrm{P}$ não pode variar de 0,50 para áreas cobertas $\mathrm{e}$ 0,25 para áreas descobertas. Já $\mathrm{A}_{\mathrm{q}}$. $\mathrm{P}$ é igual à $\mathrm{A}_{\text {const }}$.

Neste trabalho foi utilizado o valor de $\mathrm{P}$ igual a 0,50 pelo motivo acima descrito. Aplicando a formulação (2) obteve-se os valores de área (A) que correspondem a porção impermeável do imóvel ou a área construída corrigida $\left(\mathrm{A}_{\text {const.(c) }}\right)$, para os casos onde a área construída é maior que a área do terreno. Para proceder aos cálculos referentes ao Custo unitário das áreas impermeabilizadas do imóvel, o método de Tucci (2002) utiliza a seguinte formulação:

$\mathrm{C}_{\mathrm{u}_{\mathrm{i}}}=\frac{100 \cdot \mathrm{C}_{\mathrm{t}}}{\mathrm{A}_{\mathrm{b}} \cdot\left(15,8+0,842 \cdot \mathrm{A}_{\mathrm{i}}\right)}$

Onde $\mathrm{C}_{\mathrm{t}}$ é o custo total para realizar a operação e manutenção do sistema $(\mathrm{R} \$) ; \mathrm{A}_{\mathrm{b}}$ é a área da bacia $\left(\mathrm{Km}^{2}\right)$; $\mathrm{A}_{\mathrm{i}}$ é a parcela de área da bacia impermeável $(\%)$.

Pela formulação (3) a quantificação de $\mathrm{C}_{t}$ utilizou a contribuição de cada lote em função da sua testada $(\mathrm{T})$, deste modo o custo total para realizar a operação e manutenção do sistema por unidade de metro é desenhado pelo produto $\mathrm{C}_{\mathrm{t}}(\mathrm{R} \$ / \mathrm{m}) \mathrm{x}$ $\mathrm{T}(\mathrm{m})$. 
Para os custos totais de implementação $\left(\mathrm{C}_{\mathrm{tp}}\right)$, utilizou-se o custo demandado por metro linear. Na obtenção da parcela de área da bacia impermeável $\left(\mathrm{A}_{\mathrm{i}}\right)$, calculou-se a relação entre a $\mathrm{A}_{\text {const. (c) }} \mathrm{de}$ cada lote pela área da bacia $\left(\mathrm{A}_{\mathrm{b}}\right)$.

Rateio dos custos indiretos - $T x_{\text {diretos }}$

A obtenção da taxa de drenagem inerente a implementação de obras de um plano de drenagem, coadunam com os custos diretos do empreendimento. Deste modo, têm-se duas formas de contribuição, relacionada com imóveis de áreas impermeáveis e permeáveis, apresentadas pelas equações (4) e (5), respectivamente, as quais somadas obtêm-se a $\mathrm{Tx}_{\text {dire- }}$ tos.

$\mathrm{T}_{\mathrm{x}_{\mathrm{i}}}=\frac{\text { A. } \mathrm{C}_{\mathrm{t}_{\mathrm{p}} \cdot\left(15+0,75 \cdot \mathrm{i}_{\mathrm{i}}\right)}}{\mathrm{A}_{\mathrm{b}} \cdot \mathrm{A}_{\mathrm{i}}}$

$\mathrm{T}_{\mathrm{x}_{\mathrm{i}}}=\frac{15 \cdot \mathrm{A} \cdot \mathrm{C}_{\mathrm{tp}}}{\mathrm{A}_{\mathrm{b}} \cdot \mathrm{A}_{\mathrm{i}}}$

$\mathrm{Na}$ pesquisa ora realizada, elegendo como área experimental um loteamento inserido na bacia do Tucunduba, alvo do Plano de Desenvolvimento Local (PDL) realizado pela PMB no ano de 2001, o valor de $\mathrm{T}_{\mathrm{xi}}$ para a equação (4) relacionou-se com a área impermeável de cada lote $\left(\mathrm{A}_{\text {const. (c) }}\right)$. Igualmente do que fora procedido em relação à equação (5) que, pela diferença entre a $\mathrm{A}_{\text {terreno }}$ e a $\mathrm{A}_{\text {const. (c) }}$, obteve-se a porção permeável do imóvel.

\section{Método de Gomes et. al (2008)}

$\mathrm{Na}$ presente pesquisa, ainda inferiu-se sobre a taxa de drenagem, conforme estabelecido por Gomes et al. (2008). Neste processo, é pretensioso não vinculá-lo com o índice de impermeabilidade da bacia. Assim, tem-se apenas que os custos do sistema de drenagem referenciam-se, tão somente, a contribuição de cada lote e do sistema viário, sejam estes impermeáveis ou não.

Ainda assim, de acordo com Gomes et al. (2008), a valoração de uma taxa de drenagem, apesar da relação dos custos de manutenção dos sistemas de drenagem urbana não serem relacionados único e exclusivamente aos coeficientes de escoamento superficial (áreas permeáveis e impermeáveis), sabe-se que os mesmos são factíveis de avaliação pelos gestores desses sistemas, de fácil percepção pelos usuários dos mesmos como um parâmetro ligado diretamente à geração de escoamento, e até o momento, vem sendo utilizado para balizar a com- posição da taxa de drenagem, inclusive por Tucci (2002).

Deste modo, para quantificação da taxa de drenagem, considerando as prerrogativas acima elencadas, o coeficiente de escoamento superficial (runoff) para áreas impermeáveis fora adotado 0,95 e para áreas permeáveis o valor de 0,15 , conforme recomendados por Tucci (2002) na equação 6 .

Assim, o método aqui procedido estabelece uma relação dos custos de manutenção do sistema de drenagem, do qual reside a contribuição dos custos das permeáveis e impermeáveis, igualmente adotado para estabelecer a relação com os investimentos.

$\frac{\mathrm{C}_{\mathrm{i}}}{\mathrm{C}_{\mathrm{p}}}=\frac{0,95}{0,15}$

Para a obtenção dos custos de manutenção, ratificando o que descreve o item anterior, tem-se a relação dos mesmos com o runoff, conforme sugeridos por Tucci (2002).

$\mathrm{C}_{\operatorname{man}(\mathrm{i})}=6,33 \cdot \mathrm{C}_{\operatorname{man}(\mathrm{p})}$

Onde:

$\mathrm{C}_{\operatorname{man}}=\mathrm{C}_{\operatorname{man}(\mathrm{i})}+\mathrm{C}_{\operatorname{man}(\mathrm{p})}$

Substituindo a equação (7) em (8) obteremos a relação dos custos de manutenção com áreas permeáveis e impermeáveis, igual raciocínio é estendido a quantificação dos investimentos no sistema de drenagem em função de suas áreas, permeáveis e impermeáveis. Logo, as equações acima descritas refletem as mesmas interações para se fazer inferir os investimentos (I):

$\mathrm{C}_{\operatorname{man}}=6,33 \cdot \mathrm{C}_{\operatorname{man}(\mathrm{p})}+\mathrm{C}_{\operatorname{man}(\mathrm{p})}$

$\mathrm{I}=6,33 \cdot \mathrm{I}_{\mathrm{P}}+\mathrm{I}_{\mathrm{P}}$

Após a abordagem descrita acima, a fim de serem obtidas as correlações de custos de manutenção do sistema de drenagem pela equação (9), e dos investimentos do referido sistema conforme a equação (10); o método aqui aplicado difunde-se em duas componentes de valoração.

A primeira relaciona a cobrança de uma taxa que deve administrar a manutenção do sistema, e a segunda para cobrir a amortização do mesmo, como serão descritas abaixo. 
Taxas referentes aos custos com a manutenção dos sistemas $\left(T_{\operatorname{man}}\right)$

A composição básica da taxa de drenagem, referente à manutenção do sistema de drenagem, é composta dos reflexos destas com as áreas permeáveis $\left(\mathrm{T}_{\operatorname{man}(\mathrm{p})}\right)$ e impermeáveis $\left(\mathrm{T}_{\operatorname{man}(\mathrm{i})}\right)$, bem como as urbanizações ou não dos sistemas viários, $\left(\mathrm{T}_{\operatorname{man}(\mathrm{SVp})}\right)$ e $\left(\mathrm{T}_{\operatorname{man}\left(\mathrm{SV}_{i}\right)}\right)$. Logo, para a quantificação da taxa de drenagem, têm-se os seguintes componentes:

$$
\begin{aligned}
& \mathrm{T}_{\operatorname{man}(\mathrm{p})}=\frac{\mathrm{C}_{\operatorname{man}(\mathrm{p})}}{\mathrm{A}_{\mathrm{l}}} \cdot \mathrm{S}_{\mathrm{l}} \cdot\left(1-\mathrm{T}_{\mathrm{i}}\right) \\
& \mathrm{T}_{\operatorname{man}(\mathrm{i})}=\frac{\mathrm{C}_{\operatorname{man}(\mathrm{i})}}{\mathrm{A}_{\mathrm{l}}} \cdot \mathrm{S}_{\mathrm{l}} \cdot \mathrm{T}_{\mathrm{i}} \\
& \mathrm{T}_{\operatorname{man}\left(\mathrm{SV}_{\mathrm{p}}\right)}=\frac{\mathrm{C}_{\operatorname{man}(\mathrm{p})}}{A_{l}} \cdot \frac{\mathrm{A}_{\mathrm{SV}_{\mathrm{P}}}}{A_{\mathrm{b}}} \cdot \mathrm{S}_{\mathrm{l}} \\
& \mathrm{T}_{\operatorname{man}\left(\mathrm{SV}_{\mathrm{i}}\right)}=\frac{\mathrm{C}_{\operatorname{man}(\mathrm{i})}}{A_{\mathrm{l}}} \cdot \frac{\mathrm{A}_{\mathrm{SV}_{\mathrm{i}}}}{A_{\mathrm{b}}} \cdot \mathrm{S}_{\mathrm{l}}
\end{aligned}
$$

Onde $\mathrm{C}_{\text {man(p) }}$ é o custo de manutenção associado a áreas permeáveis $(\mathrm{R} \$) ; \mathrm{C}_{\operatorname{man}(\mathrm{i})}$ é o custo de manutenção associado a áreas impermeáveis $(R \$)$; $\mathrm{A}_{1}$ é a área total de lotes urbanizados ou não $\left(\mathrm{m}^{2}\right) ; \mathrm{S}_{1}$ é a área total de cada lote urbanizado ou não $\left(\mathrm{m}^{2}\right)$; $\mathrm{T}_{\mathrm{i}}$ é o índice de impermeabilização dos lotes (\%); $\mathrm{A}_{\mathrm{SV} \mathrm{p}}$ é a área pública e do sistema viário permeáveis; $\mathrm{A}_{\mathrm{SVi}}$ corresponde a área pública e do sistema viário impermeáveis. A soma das equações de 11 à 14 originam $\mathrm{T}_{\text {man }}$.

Taxas referentes aos custos de amortização dos investimentos $\left(T_{\text {inv }}\right)$

Listam-se abaixo as formulações, que agregadas, contemplam os valores de amortização dos investimentos.

$$
\begin{aligned}
& \mathrm{T}_{\operatorname{inv}(\mathrm{p})}=\frac{\mathrm{I}_{\mathrm{p}}}{\mathrm{A}_{\mathrm{l}}} \cdot \mathrm{S}_{\mathrm{l}} \cdot\left(1-\mathrm{T}_{\mathrm{i}}\right) \\
& \mathrm{T}_{\operatorname{inv}(\mathrm{i})}=\frac{\mathrm{I}_{\mathrm{i}}}{\mathrm{A}_{l}} \cdot \mathrm{S}_{\mathrm{l}} \cdot \mathrm{T}_{\mathrm{i}} \\
& \mathrm{T}_{\operatorname{inv}\left(\mathrm{SV}_{\mathrm{p}}\right)}=\frac{\mathrm{I}_{\mathrm{p}}}{\mathrm{A}_{\mathrm{l}}} \cdot \frac{\mathrm{Asv}_{\mathrm{P}}}{\mathrm{A}_{\mathrm{b}}} \cdot \mathrm{S}_{\mathrm{l}} \\
& \mathrm{T}_{\operatorname{inv}\left(\mathrm{SV}_{\mathrm{i}}\right)}=\frac{\mathrm{I}_{\mathrm{i}}}{\mathrm{A}_{\mathrm{l}}} \cdot \frac{\mathrm{Asv}_{\mathrm{i}}}{\mathrm{A}_{\mathrm{b}}} \cdot \mathrm{S}_{\mathrm{l}}
\end{aligned}
$$

Onde $I_{p}$ é a amortização dos investimentos associados a áreas permeáveis ( $\mathrm{R} \$ / \mathrm{ano})$; Ii corresponde a amortização dos investimentos associados a áreas impermeáveis $(\mathrm{R} \$ / \mathrm{ano})$. A soma das equações de 15 a 18 originam a $\mathrm{T}_{\text {inv }}$. Deste modo, a soma de $\mathrm{T}_{\text {man }}$ e $\mathrm{T}_{\text {inv }}$ totaliza a taxa de drenagem anual conforme preceitua Gomes et. al (2008).

\section{ANÁLISE DOS RESULTADOS}

\section{Resultados obtidos para Tucci (2002)}

A metodologia proposta por Tucci caracteriza duas formas de contribuição, como descrito anteriormente, o rateio dos custos diretos e indiretos de um plano de drenagem. Para estes, foram analisados três possibilidade de cobrança, uma em relação à área do imóvel (impermeável + permeável), outra em função da renda familiar e o último a testada dos imóveis, direcionado à AEC em questão, inserida na bacia hidrográfica do Tucunduba.

Tais prerrogativas propiciarão ferramentas para prognosticar a arrecadação municipal a fim de auto-sustentar um plano de drenagem urbana no município de Belém/PA.

\section{Taxa de Drenagem x Área do Imóvel}

Para estabelecer a relação entre a taxa de drenagem em função da área do imóvel, foi primeiramente procedido o cálculo da taxa de drenagem para os custos diretos $\left(T x_{\text {direto }}\right)$ e indiretos $\left(T x_{\text {indireto }}\right)$, conforme preconizado pelo método de Tucci (2002).

Deste modo, foi percebido que a taxa de contribuição para o rateio dos custos indiretos confrontando com a área do imóvel apresenta forte correlação $\left(\mathrm{R}^{2}=0,966\right)$, que para o conjunto amostral da AEC o ajuste dos dados é representado por uma equação linear.

Não obstante que para o rateio dos custos diretos de um plano de drenagem, como é mostrado na Figura 2A, a relação é estabelecida por um comportamento linear, tanto para o que concerne as taxas relacionadas a áreas impermeáveis ( $\mathrm{Tx}$ $\left.\mathrm{Ai}_{[\text {c.diretos] }}\right)$, quanto para as áreas permeáveis ( $\mathrm{Tx}$ $\left.\operatorname{Ap}_{[\text {c.diretos }]}\right)$.

Os custos de implementação de um sistema de drenagem, para áreas impermeáveis maiores que $55,0 \mathrm{~m}^{2}$, apresentou valor igual a $\mathrm{R} \$ 0,029 /$ ano. Para uma área maior que $63,0 \mathrm{~m}^{2}$ o valor de $\mathrm{Tx}$ $\mathrm{Ap}_{\text {[c.diretos] }}$ foi igual a $\mathrm{R} \$ 0,014 /$ ano.

Tais resultados indicam que, para áreas impermeáveis inferiores a $55,0 \mathrm{~m}^{2}$ os custos diretos de um plano de drenagem devem ser sustentados pelos custos de manutenção e operação do sistema, o 
mesmo raciocínio é estendido para áreas permeáveis inferiores a $63,0 \mathrm{~m}^{2}$ por se tratar de custos reduzidos.

As taxas relativas ao rateio dos custos de manutenção e operação de um sistema de drenagem urbana seguem a mesma tendência dos custos diretos. Para a $T x_{\text {indireto }}$ o ajuste realizado à distribuição dos valores pautados na AEC proporcionou excelente correlação entre os rateios da taxa de drenagem formulados por Tucci (2002) em relação à área do imóvel, conforme a Figura 2B.

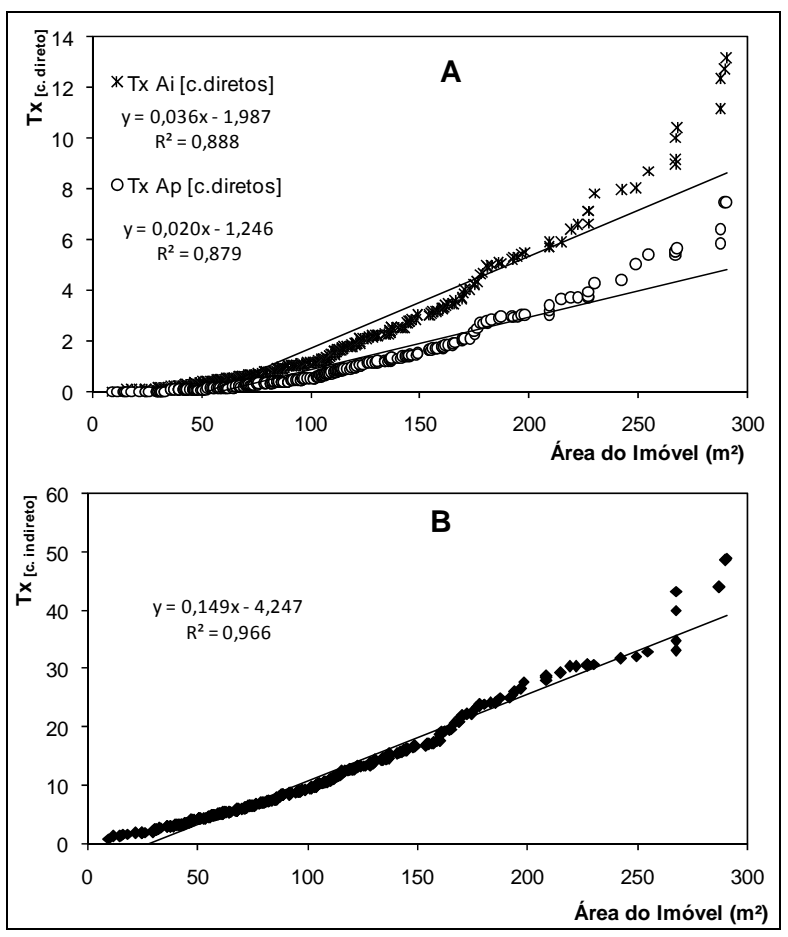

Figura 2 - Relação entre a taxa de drenagem e a área para a AEC.

Neste sentido, quanto maior for a área impermeabilizada maior será a taxa de drenagem, como era de se esperar. Para áreas do imóvel inferiores a 28,0 $\mathrm{m}^{2}$ os custos inerentes à manutenção e operação dos sistemas devem ser subsidiados.

Para a AEC, apresenta-se em seu conjunto amostral um Coeficiente de Variação de 68,81\%, onde a área do terreno média é de $113,37 \mathrm{~m}^{2}$ a Taxa de Drenagem ficaria em torno de $\mathrm{R} \$ 15,76 /$ ano. Ressalta-se que a referida localidade tem uma renda média de $2 \mathrm{SM}$, portanto tais ponderações mostram que o método é compatível com a realidade da área em análise.

Dentre os parâmetros de cálculo do método de Tucci (2002), pertinentes a esta análise, desta- cam-se o $i_{1}$ que foi de $66,10 \%$ e o $A_{i}$ médio de $46,33 \%$, e o $\mathrm{Cu}_{\mathrm{i}}$ médio de $\mathrm{R} \$ 0,37 / \mathrm{m}^{2}$.

As análises aqui desenhadas denotam correlações que premeditam a extrapolação para as outras unidades hidrográficas do município de Belém/PA, deste modo com o conhecimento da área dos imóveis é possível predizer qual a taxa de drenagem a ser cobrada, e ainda, os valores das mesmas em função dos custos diretos, das áreas permeáveis e impermeáveis, e dos custos indiretos de um sistema de drenagem urbana.

O método proposto por Tucci (2002), neste caso, apresentou uma tendência para a manutenção do sistema de drenagem em comparação aos custos diretos de implementação. A simulação realizada com os ajustes procedidos acima mostra que $\mathrm{R} \$$ 9,17 /ano é a diferença média entre $\mathrm{Tx}_{\text {indireto }} \mathrm{e} \mathrm{o}$ $\mathrm{Tx}_{\text {direto }}$, e a taxa de drenagem cresce proporcionalmente quanto maior for à área do imóvel.

Quadro 1 - Simulação da Taxa de Drenagem x Área

\begin{tabular}{c|c|c|c}
\hline \multirow{2}{*}{$\mathbf{A}_{\text {imóvel }}\left(\mathbf{m}^{2}\right)$} & $\mathbf{T x}_{\text {indireto }}$ & \multicolumn{2}{|c}{$\begin{array}{c}\mathbf{T} \mathbf{x}_{\text {direto }} \\
(\mathbf{R} \mathbf{\text { \$ano }})\end{array}$} \\
\cline { 3 - 4 } & & $\mathbf{A}_{\text {imp }}$ & $\mathbf{A}_{\mathbf{p}}$ \\
\hline 0,0 & $-4,247$ & $-1,987$ & $-1,246$ \\
\hline 50 & 3,203 & $-0,187$ & $-0,246$ \\
\hline 100 & 10,653 & 1,613 & 0,754 \\
\hline 150 & 18,103 & 3,413 & 1,754 \\
\hline 200 & 25,553 & 5,213 & 2,754 \\
\hline 250 & 33,003 & 7,013 & 3,754 \\
\hline 300 & 40,453 & 8,813 & 4,754 \\
\hline 350 & 47,903 & 10,613 & 5,754 \\
\hline 400 & 55,353 & 12,413 & 6,754 \\
\hline 450 & 62,803 & 14,213 & 7,754 \\
\hline 500 & 70,253 & 16,013 & 8,754 \\
\hline
\end{tabular}

\section{Taxa de Drenagem $x$ Testada do Imóvel}

As análises pertinentes a taxa de drenagem a fim de cobrir os custos diretos de implementação de um sistema de drenagem, desta vez, são correlacionados com a testada dos imóveis para a AEC.

Não diferentemente com o que ocorrera quando correlacionada com a área do imóvel, observou-se um ajuste linear ao comportamento das taxas de drenagem, onde a melhor correlação obtida foi para áreas impermeáveis $\left(\mathrm{R}^{2}=0,909\right)$, e para as áreas permeáveis $\mathrm{R}^{2}=0,899$ (Figura 3A). 


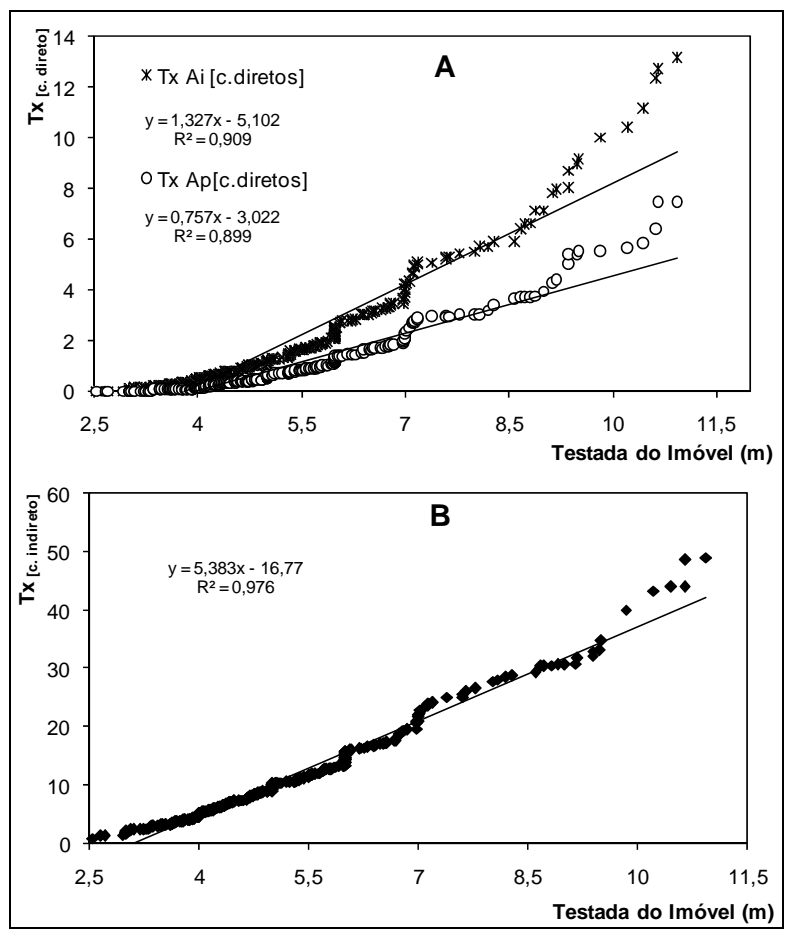

Figura 3 - Relação entre a taxa de drenagem e testada para a AEC.

Tais análises denotam que quanto maior for a testada do imóvel, maior será a sua contribuição para com os custos diretos de um plano de drenagem.

Ressalta-se que mesmo para imóveis com testadas significativas e com áreas $100 \%$ permeáveis, considera-se a cobrança de taxas. Pois, estas áreas são parte integrante da bacia hidrográfica e beneficiadas com as intervenções preventivas e/ ou corretivas na drenagem urbana. Deste modo, tais ponderações são pertinentes.

A taxa de drenagem relacionada aos custos indiretos de manutenção e operação do sistema quando correlacionado com a testada dos imóveis da AEC apresentou $\mathrm{R}^{2}=0,976$. Vê-se, tal prognóstico, como elemento norteador para a cobrança de taxa de drenagem correlacionando-o com o parâmetro Testada (Figura 3B).

Para testadas inferiores a 3,0 $\mathrm{m}$, os valores de $T x_{\text {indireto }}$ e $T x_{\text {direto }}$ apresentaram valores negativos. Significando analisar que tais valores representam ônus ao estado em forma de subsídios.

Em função das equações originadas pelas análises acima postuladas, fez-se uma simulação com valores de testada variando de 3,0 m, vistas no Quadro 2.
Quadro 2 - Simulação da Taxa de Drenagem x Testada

\begin{tabular}{c|c|c|c}
\hline \multirow{2}{*}{ Testada (m) } & \multirow{2}{*}{$\begin{array}{c}\text { T. } \\
(\mathbf{R} \text { indireto }\end{array}$} & \multicolumn{2}{|c}{$\begin{array}{c}\mathbf{T} \mathbf{x}_{\text {direto }} \\
(\mathbf{R} \mathbf{\$} / \mathbf{a n o})\end{array}$} \\
\cline { 3 - 4 } & & $\mathbf{A}_{\text {imp }}$ & $\mathbf{A}_{\mathbf{p}}$ \\
\hline 1 & $-11,387$ & $-3,775$ & $-2,265$ \\
\hline 4 & 4,762 & 0,206 & 0,006 \\
\hline 6 & 15,528 & 2,86 & 1,52 \\
\hline 9 & 31,677 & 6,841 & 3,791 \\
\hline 12 & 47,826 & 10,822 & 6,062 \\
\hline 15 & 63,975 & 14,803 & 8,333 \\
\hline 18 & 80,124 & 18,784 & 10,604 \\
\hline 21 & 96,273 & 22,765 & 12,875 \\
\hline 24 & 112,422 & 26,746 & 15,146 \\
\hline 27 & 128,571 & 30,727 & 17,417 \\
\hline 30 & 144,72 & 34,708 & 19,688 \\
\hline
\end{tabular}

Em termos gerais, as taxas referentes aos custos indiretos são superiores quando comparadas com as dos custos de implementação. Assim, o método formulado por Tucci (2002) enaltece, para este caso, um viés preventivo, mostrando-se aplicativo para o planejamento e a autosustenção de um sistema de drenagem urbana.

\section{Taxa de Drenagem $x$ Renda Familiar}

Por fim, foi estabelecida na presente pesquisa outra forma de correlacionar a cobrança para o financiamento da drenagem urbana por meio da correlação da taxa de drenagem pelo método de Tucci (2002) em função da renda familiar, experimentado na AEC.

Tais relações mostraram-se complexas, pois os ajustes se deram por meio de uma equação polinomial de $2^{2}$ Ordem, tanto para a $T x_{\text {indireto }}$ e Tx Ai

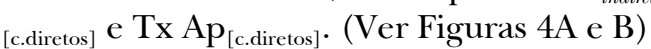

As taxas destinadas a cobrir os custos diretos, quando não há renda familiar, relacionados a áreas permeáveis devem ser subsidiadas por apresentarem valores negativos. No entanto, quanto maior for a renda, maior será a contribuição a ser cobrada que para o caso em questão ficou em torno de $0,68 \%$ a cada acréscimo do número de SM.

No que tange a $\mathrm{Tx} \mathrm{Ai}_{[\text {c.diretos] }}$, o método apresentou limitações quanto a sua aplicabilidade, já que quando não há renda os valores a serem cobrados são de $\mathrm{R} \$ 0,125 /$ ano, com acréscimo no número de $\mathrm{SM}$ de $0,67 \%$. 
Não obstante, o rateio dos custos destinado a manutenção, foi da ordem de $\mathbf{R} \$ 2,55 /$ ano com $0,57 \%$ de acréscimo a cada aumento no número de SM por parte do contribuinte.

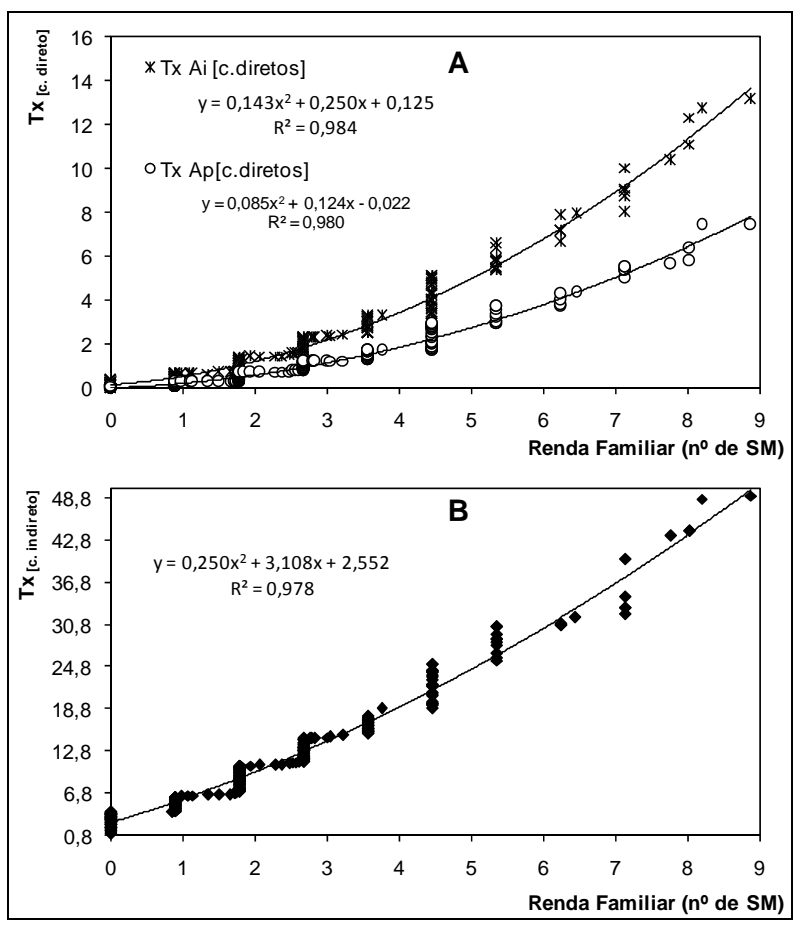

Figura 4 - Relação entre a taxa de drenagem e a renda familiar para a AEC.

Quadro 3 - Simulação da Taxa de Drenagem x Renda.

\begin{tabular}{|c|c|c|c|}
\hline \multirow{2}{*}{$\begin{array}{c}\text { Renda } \\
\text { Familiar } \\
\left(n^{\circ} \text { de } S M\right)\end{array}$} & \multirow{2}{*}{$\begin{array}{c}T \mathbf{x}_{\text {indireto }} \\
(\mathbf{R} \mathbf{\text { ano }})\end{array}$} & \multicolumn{2}{|c|}{$\begin{array}{c}\mathbf{T x}_{\text {direto }} \\
\text { (R\$/ano) }\end{array}$} \\
\hline & & $\mathbf{A}_{\mathrm{imp}}$ & $A_{p}$ \\
\hline 0 & 2,552 & 0,125 & $-0,022$ \\
\hline 1 & 5,91 & 0,518 & 0,187 \\
\hline 2 & 9,768 & 1,197 & 0,566 \\
\hline 3 & 14,126 & 2,162 & 1,115 \\
\hline 4 & 18,984 & 3,413 & 1,834 \\
\hline 5 & 24,342 & 4,95 & 2,723 \\
\hline 6 & 30,2 & 6,773 & 3,782 \\
\hline 7 & 36,558 & 8,882 & 5,011 \\
\hline 8 & 43,416 & 11,277 & 6,41 \\
\hline 9 & 50,774 & 13,958 & 7,979 \\
\hline 10 & 58,632 & 16,925 & 9,718 \\
\hline
\end{tabular}

As relações obtidas a partir do cálculo da taxa de drenagem em função do número de SM, mos- trou-se teoricamente aplicável, mas não exeqüível socialmente (Quadro 3).

Todavia, é preciso salientar que para a AEC experimental por ser detentora de uma faixa de renda média de $2 \mathrm{SM}$, as prerrogativas acima elencada mostraram-se pouco pertinentes.

Em áreas onde há uma faixa de renda mais elevada às correlações aqui obtidas soam como mecanismos de ponderação para que seja estabelecida a cobrança de taxa subsidiando ações no sistema de drenagem urbana do município de Belém/PA

Por fim tem-se um comparativo entre os parâmetros correlacionados para quantificar a taxa de drenagem pelo método de Tucci (2002), conforme demonstrada pelo Quadro 4.

Quadro 4 - Taxa de Drenagem média em função dos parâmetros correlacionados obtidos para a AEC.

\begin{tabular}{l|l|l|l|l}
\hline \multirow{2}{*}{} & \multicolumn{4}{|l}{$\mathbf{T x}_{\mathbf{T}}(\mathbf{R} \mathbf{a} / \mathbf{a n o})$} \\
\cline { 2 - 5 } & $\mathbf{T x}_{\mathbf{T}(\mathbf{m} \text { édio) }}$ & $\delta \mathbf{T x}_{\mathbf{T}}{ }^{(*)}$ & $\boldsymbol{\beta}^{(* *)}$ & $\mathbf{R}^{\mathbf{2}}$ \\
\hline $\mathbf{A}$ & 0,151 & 0,046 & $30,30 \%$ & 0,950 \\
\hline $\mathbf{T}$ & 4,85 & 5,44 & $121,12 \%$ & 0,965 \\
\hline $\mathbf{S M}$ & 8,97 & 2,44 & $27,22 \%$ & 0,947 \\
\hline
\end{tabular}

Os caracteres ${ }^{(*)}$ e $(* *)$ são o Desvio padrão e Coeficiente de variação $\left(\delta \mathrm{Tx}_{\mathrm{T}} / \mathrm{Tx}_{\mathrm{T}(\text { médio })} \mathrm{x} 100\right)$, respectivamente. A - Área do Imóvel; T - Testada; $\mathrm{SM}$ - n⿳ํㅡㄹ de Salário Mínimo.

Nota-se que o parâmetro testada não se distribui uniformemente no conjunto amostral, e ainda apresenta grandes variações, descartando esta correlação para quantificar a taxa de drenagem.

Logo, por apresentar significativa correlação, e coeficientes de variação próximos, elege-se a área do imóvel e a renda familiar para serem utilizados como ferramentas para quantificar a taxa de drenagem a ser cobrada.

Ressalta-se que as correlações entre $\mathrm{a} \mathrm{Tx}_{\mathrm{T}}$ e a renda familiar, limitada pela sua aplicabilidade, e entre a testada, estas podem ser atrativos para a mensuração da taxa de drenagem em zonas preferenciais de Belém/PA das quais estas informações sejam preponderantes.

\section{Resultados obtidos para Gomes et. al (2008)}

A metodologia proposta por Gomes et. al (2008), não faz alusão ao índice de impermeabilização da bacia, mas, quantifica os custos do sistema de 
drenagem pela contribuição de cada lote e das vias públicas, sejam estes urbanizados ou não.

A taxa de drenagem calculada para o método de Gomes et. al (2008) considera dois aspectos: taxa de manutenção/operação $\left(\mathrm{T}_{\operatorname{man}}\right)$ e de amortização dos investimentos $\left(\mathrm{T}_{\mathrm{inv}}\right)$. Ambas as taxas são correlacionadas pelo parâmetro área e testadas do imóvel, bem como pela renda familiar.

\section{Taxa de Drenagem x Área do Imóvel}

As análises pertinentes a taxa de drenagem ( $\mathrm{T}_{\operatorname{man}} \mathrm{e} \mathrm{T}_{\text {inv }}$ ) correlacionadas com a área do imóvel, obtidas pela inferência do método de Gomes et. al (2008) na AEC, estão expressas pela Figura 5.

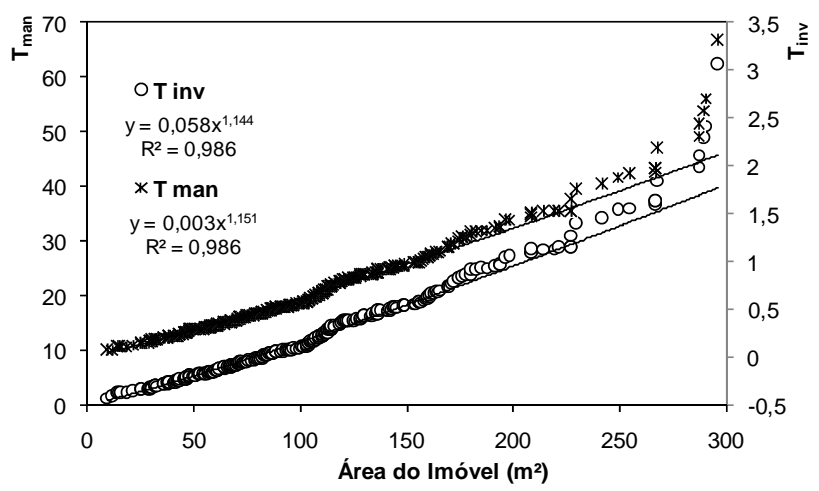

Figura 5 - Relação entre a Taxa de Drenagem e a Área do Imóvel obtido nas análises feitas na AEC.

Os ajustes realizados para os dados ora copilados e correlacionados foram desenhados por equações potenciais, das quais, coincidentemente, foram obtidas excelentes correlações iguais a $\mathrm{R}^{2}=$ 0,986 .

Portanto, tais relações podem ser ferramentas capazes de quantificar taxas de drenagem para financiamento do setor de drenagem urbana do município de Belém/PA.

As taxas de manutenção e operação do sistema a partir de Área do Imóvel $>0,0 \mathrm{~m}^{2}$, crescem proporcionalmente a suas áreas, e para áreas superiores a 2,0 $\mathrm{m}^{2}$ para quantificações de taxas para amortização dos investimentos.

Para as correlações ora estabelecidas, percebeu-se que em média $94,88 \%$ da taxa de drenagem são destinadas para a manutenção e operação, enquanto que os 5,12\% para a amortização dos investimentos de implementação.
Feitas as simulações produzidas a partir das correlações obtidas pela taxa de drenagem e a área do imóvel obtêm-se o seguinte (Quadro 5):

Quadro 5 - Simulação da Taxa de Drenagem x Área

\begin{tabular}{l|l|l|l|l}
\hline \multirow{2}{*}{$\begin{array}{c}\mathrm{A}_{\text {imóvel }} \\
\left(\mathrm{m}^{2}\right)\end{array}$} & \multicolumn{2}{|l|}{$\mathrm{T}_{\text {man }}$} & \multicolumn{2}{l}{$\mathrm{T}_{\text {inv }}$} \\
\cline { 2 - 5 } & $\mathrm{R} \$ /$ ano & $\mathrm{T}_{\operatorname{man}} / \mathrm{Tx}_{\mathrm{G}}$ & $\mathrm{R} \$ /$ ano & $\mathrm{T}_{\text {inv }} / \mathrm{Tx}_{\mathrm{G}}$ \\
\hline 0,0 & 0,00 & $0,0 \%$ & $-4,247$ & $0,0 \%$ \\
\hline 50 & 0,27 & $5,05 \%$ & 3,203 & $94,95 \%$ \\
\hline 100 & 0,60 & $5,07 \%$ & 10,653 & $94,93 \%$ \\
\hline 150 & 0,96 & $5,08 \%$ & 18,103 & $94,92 \%$ \\
\hline 200 & 1,34 & $5,09 \%$ & 25,553 & $94,91 \%$ \\
\hline 250 & 1,73 & $5,10 \%$ & 33,003 & $94,90 \%$ \\
\hline 300 & 2,13 & $5,11 \%$ & 40,453 & $94,89 \%$ \\
\hline 350 & 2,54 & $5,11 \%$ & 47,903 & $94,89 \%$ \\
\hline 400 & 2,97 & $5,12 \%$ & 55,353 & $94,88 \%$ \\
\hline 450 & 3,40 & $5,12 \%$ & 62,803 & $94,88 \%$ \\
\hline 500 & 3,83 & $5,13 \%$ & 70,253 & $94,87 \%$ \\
\hline
\end{tabular}

O método de Gomes et al. (2008), enveredou-se a ponderar sobre a taxa que cobre a amortização dos investimentos à manutenção. Para o caso em questão, tal método denotou um caráter assistencialista, diferentemente o que revelou o método de Tucci (2002).

Como mecanismo de financiamento para o aporte de captação de recursos, tal método atendeu ao objetivo da pesquisa, pois o mesmo proporciona fontes de auto-sustentação de um sistema de drenagem obtidas a partir da AEC na cidade de Belém/PA.

Observou-se que quanto maior a área do imóvel, maior será a contribuição à taxa de drenagem, donde, como supracitado, a maior parte desta taxa é destinada a cobrir os investimentos empenhados para implementar um plano de drenagem.

\section{Taxa de Drenagem x Testada do Imóvel}

A testada do imóvel pode ser um parâmetro para quantificar a taxa de drenagem anual a ser cobrada. Para testadas inferiores a 2,5 m, a taxa de drenagem, tanto a $\mathrm{T}_{\text {man }}$ quanto a $\mathrm{T}_{\text {inv, }}$, resultam em valores negativos, isto é, os custos agregados ao financiamento do plano de drenagem, devem ser subsidiados. 
No entanto, é percebido que as relações entre os parâmetros aqui analisados são ajustadas por equações polinomiais de $2^{\underline{a}}$ ordem, refletindo sua complexidade; mas, apresentando forte correlação e de iguais valores $\left(\mathrm{R}^{2}=0,985\right)$.

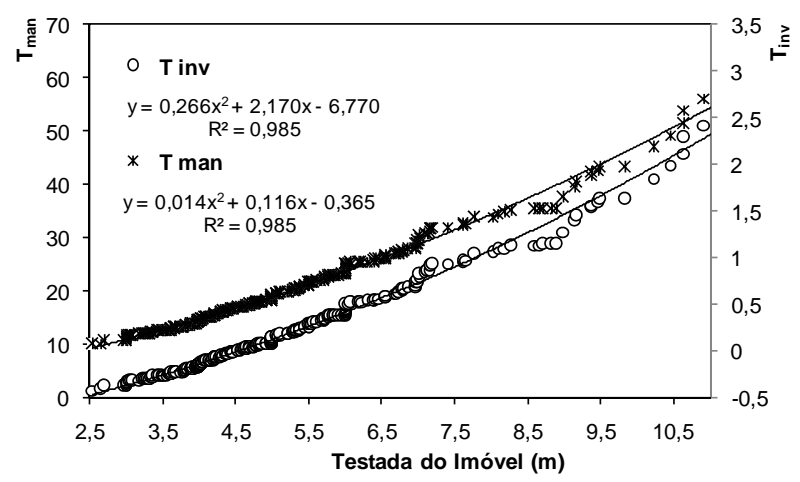

Figura 6 - Relação entre a Taxa de Drenagem e a Testada do Imóvel obtido nas análises feitas na AEC

Realizadas as simulações, a partir das equações obtidas, tem-se que taxa de drenagem média a ser cobrada fica em torno de $\mathrm{R} \$ 9,78 /$ ano.m, sendo que $95,05 \%$ pertencem a $\mathrm{T}_{\text {inv }}$, e o restante, $5,95 \%$ a $\mathrm{T}_{\operatorname{man}}$ (Quadro 6).

Quadro 6 - Simulação da Taxa de Drenagem x Testada

\begin{tabular}{c|c|c|c|c}
\hline \multirow{2}{*}{$\begin{array}{c}\text { Testada } \\
(\mathrm{m})\end{array}$} & \multicolumn{2}{|c|}{$\mathrm{T}_{\text {man }}$} & \multicolumn{2}{c}{$\mathrm{T}_{\text {inv }}$} \\
\cline { 2 - 5 } & $\mathrm{R} \$ /$ ano & $\mathrm{T}_{\text {man }} / \mathrm{Tx}_{\mathrm{G}}$ & $\mathrm{R} \$ /$ ano & $\mathrm{T}_{\text {inv }} / \mathrm{Tx}_{\mathrm{G}}$ \\
\hline 1 & $-0,235$ & $5,14 \%$ & $-4,334$ & $94,86 \%$ \\
\hline 4 & 0,323 & $4,98 \%$ & 6,166 & $95,02 \%$ \\
\hline 6 & 0,835 & $5,01 \%$ & 15,826 & $94,99 \%$ \\
\hline 9 & 1,813 & $5,02 \%$ & 34,306 & $94,98 \%$ \\
\hline 12 & 3,043 & $5,02 \%$ & 57,574 & $94,98 \%$ \\
\hline 15 & 4,525 & $5,02 \%$ & 85,63 & $94,98 \%$ \\
\hline 18 & 6,259 & $5,02 \%$ & 118,474 & $94,98 \%$ \\
\hline 21 & 8,245 & $5,02 \%$ & 156,106 & $94,98 \%$ \\
\hline 24 & 10,483 & $5,02 \%$ & 198,526 & $94,98 \%$ \\
\hline 27 & 12,973 & $5,01 \%$ & 245,734 & $94,99 \%$ \\
\hline 30 & 15,715 & $5,01 \%$ & 297,73 & $94,99 \%$ \\
\hline
\end{tabular}

Taxa de Drenagem $x$ Renda Familiar

Por fim, é procedido a correlação entre a taxa de drenagem, calculada para a AEC por meio do método de Gomes et. al (2008), e a renda familiar da referida área de pesquisa.

Notou-se certa complexidade nesta correlação, pelo ajuste das curvas, tanto para as $\mathrm{T}_{\text {inv }}$ como para a $\mathrm{T}_{\text {man }}$, por se comportarem como uma equação polinomial de $2^{\underline{a}}$ ordem, obtendo-se correlações, coincidentemente iguais a $\mathrm{R}^{2}=0,972$, como visualizados pela Figura 7 .

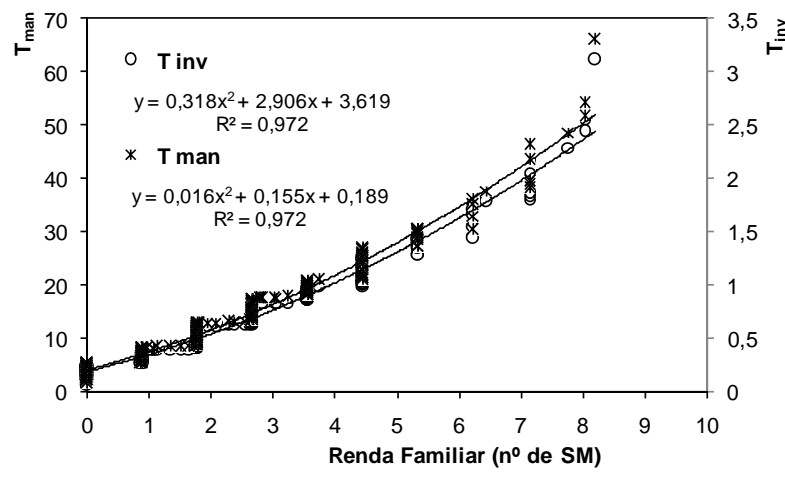

Figura 7 - Relação entre a Taxa de Drenagem e a Renda Familiar obtido nas análises feitas na AEC

Não obstante, que igualmente acontecido com o método de Tucci, a metodologia de Gomes et al. (2008), para este caso, não se apresenta como um alternativa socialmente exeqüível para a cobrança da taxa de drenagem. Quando a renda familiar é inferior a $1 \mathrm{SM}$ os custos não são subsidiados.

Quadro 7 - Simulação da Taxa de Drenagem x Renda.

\begin{tabular}{c|c|c|c|c}
\hline \multirow{2}{*}{$\begin{array}{c}\text { Renda } \\
\left(\mathrm{n}^{\circ} \mathrm{SM}\right)\end{array}$} & \multicolumn{2}{|c|}{$\mathrm{T}_{\text {man }}$} & \multicolumn{2}{c}{$\mathrm{T}_{\mathrm{inv}}$} \\
\cline { 2 - 5 } & $\mathrm{R} \$ /$ ano & $\mathrm{T}_{\text {man }} / \mathrm{Tx}_{\mathrm{G}}$ & $\mathrm{R} \$ /$ ano & $\mathrm{T}_{\text {inv }} / \mathrm{Tx}_{\mathrm{G}}$ \\
\hline 0 & 0,189 & $4,96 \%$ & 3,619 & $95,04 \%$ \\
\hline 1 & 0,36 & $5,00 \%$ & 6,843 & $95,00 \%$ \\
\hline 2 & 0,563 & $5,00 \%$ & 10,703 & $95,00 \%$ \\
\hline 3 & 0,798 & $4,99 \%$ & 15,199 & $95,01 \%$ \\
\hline 4 & 1,065 & $4,98 \%$ & 20,331 & $95,02 \%$ \\
\hline 5 & 1,364 & $4,97 \%$ & 26,099 & $95,03 \%$ \\
\hline 6 & 1,695 & $4,96 \%$ & 32,503 & $95,04 \%$ \\
\hline 7 & 2,058 & $4,95 \%$ & 39,543 & $95,05 \%$ \\
\hline 8 & 2,453 & $4,94 \%$ & 47,219 & $95,06 \%$ \\
\hline 9 & 2,88 & $4,93 \%$ & 55,531 & $95,07 \%$ \\
\hline 10 & 3,339 & $4,92 \%$ & 64,479 & $95,08 \%$ \\
\hline
\end{tabular}


Realizada uma simulação, tendo como perspectiva a extrapolação dos resultados aqui obtidos a outras áreas do município de Belém/PA, obteve-se que a $\mathrm{Tx}_{\mathrm{G}}$ média em função da renda familiar foi de $\mathrm{R} \$ 7,25 /$ ano.SM, dos quais $95,07 \%$ são de $\mathrm{T}_{\text {inv }} \mathrm{e}$ $4,93 \%$ a $\mathrm{T}_{\text {man }}$, mostradas no Quadro 7.

Os resultados obtidos pelo método de Gomes et. al (2008), apresentaram-se melhor distribuídos. Tendo este como melhor ferramenta para quantificar a taxa de drenagem, neste caso, a relação com a área do imóvel por apresentar um $\beta$ igual a $11,02 \%$ e, ainda uma significativa correlação (Quadro 8).

Quadro 8 - Taxa de Drenagem média em função dos parâmetros correlacionados obtidos para a AEC.

\begin{tabular}{l|l|l|l|l}
\hline \multirow{2}{*}{} & \multicolumn{4}{|l}{$\mathbf{T} \mathbf{x}_{\mathbf{G}} \mathbf{( R \mathbf { R } / \mathbf { a n o } )}$} \\
\cline { 2 - 5 } & $\mathbf{T} \mathbf{x}_{\mathbf{G}(\text { médio) }}$ & $\boldsymbol{\delta} \mathbf{T x}_{\mathbf{G}}{ }^{(*)}$ & $\boldsymbol{\beta}^{(* *)}$ & $\mathbf{R}^{\mathbf{2}}$ \\
\hline $\mathbf{A}$ & 0,1466 & 0,0162 & $11,02 \%$ & 0,962 \\
\hline $\mathbf{T}$ & 9,545 & 5,925 & $62,08 \%$ & 0,972 \\
\hline $\mathbf{S M}$ & 7,253 & 1,500 & $20,68 \%$ & 0,949 \\
\hline
\end{tabular}

Todavia, as correlações mostram-se como poderosas ferramentas para se quantificar a taxa de drenagem, sobretudo, quando se tratar de zonas de difícil medição de áreas, ou áreas onde a renda familiar é mais elevada, proporcionando melhor perspectiva de arrecadação municipal, atendo aos objetivos desta pesquisa, dependendo assim de qual zona a ser mensurada.

Destarte, procedem-se as análises e aplicações dos métodos aplicados neste trabalho, como mecanismo de auto-sustentação do setor.

\section{CONCLUSÕES}

As análises estabeleceram formas de quantificar a taxa de drenagem, por dois processos metodológicos, em função de três parâmetros: a área do imóvel, a sua testada e pela renda familiar.

Deste modo, o presente trabalho fundamenta e proporciona ao gestor público mecanismo de planejamento e gestão dos recursos hídricos, mais especificamente ao setor de drenagem urbana, propiciando a auto-sustentação do setor.

Portanto, como fôra visto o método de Tucci (2002) $\left[\mathrm{Tx}_{\mathrm{T}}\right]$, elegeu, para este caso, e, a fim de que essas correlações sejam extrapoladas ao município de Belém, duas importantes formas: pela área do imóvel e pela renda familiar de cada imóvel.
Para o método de Gomes et. al (2008) $\left[\mathrm{Tx}_{\mathrm{G}}\right]$, as três formas para quantificar a taxa de drenagem mostraram-se exeqüíveis, salvaguardando algumas limitações com a testada por apresentar um $\beta$ igual a $62,08 \%$.

Em uma abordagem comparativa entre os métodos adotadas na pesquisa, correlacionado-os com os parâmetros adotados, têm-se:

Quadro 9 - Taxa de Drenagem dos métodos x Área do Imóvel (A), Testada (B) e Renda Familiar (C).

\begin{tabular}{c|c|c|c|c|c|c}
\hline \multirow{2}{*}{$\mathrm{R} \$ /$ ano } & \multicolumn{7}{|c}{ Área do Imóvel $\left(\mathrm{m}^{2}\right)-(\mathrm{A})$} \\
\cline { 2 - 7 } & $\mathbf{0}$ & $\mathbf{1 0 0}$ & $\mathbf{2 0 0}$ & $\mathbf{3 0 0}$ & $\mathbf{4 0 0}$ & $\mathbf{5 0 0}$ \\
\hline $\mathrm{Tx}_{\mathrm{T}}$ & $-7,48$ & 13,02 & 13,02 & 33,52 & 54,02 & 74,52 \\
\hline $\mathrm{Tx}_{\mathrm{G}}$ & 0,0 & 11,86 & 26,21 & 41,69 & 57,94 & 74,80 \\
\hline \multirow{2}{*}{$\mathrm{R} \$$ /ano } & \multicolumn{7}{|c}{ Testada do Imóvel $(\mathrm{m})-(\mathrm{B})$} \\
\cline { 2 - 7 } & $\mathbf{5}$ & $\mathbf{1 0}$ & $\mathbf{1 5}$ & $\mathbf{2 0}$ & $\mathbf{2 5}$ & $\mathbf{3 0}$ \\
\hline $\mathrm{Tx}_{\mathrm{T}}$ & 12,44 & 49,78 & 87,11 & 124,45 & 161,78 & 199,12 \\
\hline $\mathrm{Tx}_{\mathrm{G}}$ & 11,30 & 43,73 & 90,16 & 150,59 & 225,02 & 313,45 \\
\hline \multirow{2}{*}{$\mathrm{R} \$ /$ ano } & $\mathbf{0}$ Renda Familiar $\left(\mathrm{n}^{\circ} \mathrm{de}\right.$ & $\mathrm{SM})-(\mathrm{C})$ \\
\cline { 2 - 7 } & $\mathbf{0}$ & $\mathbf{1}$ & $\mathbf{3}$ & $\mathbf{5}$ & $\mathbf{7}$ & $\mathbf{1 0}$ \\
\hline $\mathrm{Tx}_{\mathrm{T}}$ & 2,66 & 6,62 & 17,40 & 32,02 & 50,45 & 85,28 \\
\hline $\mathrm{Tx}_{\mathrm{G}}$ & 3,81 & 7,20 & 16,00 & 27,46 & 41,60 & 67,82 \\
\hline
\end{tabular}

Notadamente, o parâmetro Testada é o que mais agrega valor a taxa de drenagem para ambos os métodos, destacando-se o de Gomes et. al (2008).

Assim, a extrapolação de tais modelos urge como uma perspectiva de gerenciamento e planejamento do sistema de drenagem urbana e podem ser direcionada a zoneamento de uso e ocupação do solo do município.

\section{AGRADECIMENTOS}

À Fundação de Amparo e Apoio à Pesquisa do Estado do Pará (FAPESPA), conveniado com a Companhia Vale do Rio Doce, pelo apoio financeiro com concessão de bolsa de estudo para realização desta pesquisa (Edital no 021/2008). Aos revisores da ABRH pela contribuição na edição deste artigo.

\section{REFERENCIAS}

ANTENER, M. La Revalorisation des mileux naturales em sites périurbains et La gestion de risque d'inondation para 
dês actions à l'échelles privative - l'exemple de La ville de Zurich, Journée dínformation Aménagement et Eaux Pluviales, Lyon: GRAIE, p. 24-25, 1999;

BAPTISTA, M.B; NASCIMENTO, N.O. "Aspectos institucionais e de financiamento dos sistemas de drenagem urbana", Revista Brasileira de Recursos Hídricos, volume 7, no. 1, Jan/Mar 2002, p. 29-49;

BARRAQUÉ, B. Les politiques del'eau em Europe. Paris: Ed. La Decouverte, Paris, 303 p., 1995;

BELÉM, Lei Municipal n 8.655/08, de 30 de julho de 2008. Dispõe sobre o Plano Diretor do Município de Belém, e dá outras providências. Diário Oficial [do Estado do Pará]. Pará, v. 03, n. 6, p.70 , 30. out. 2008, Seção. 1, pt.

BRASIL, Lei Federal n 5.172/66, de 25 de outubro de 1966. Dispõe sobre o Sistema Tributário Nacional e institui normas gerais de direito tributário aplicáveis à União, Estados e Municípios. Diário Oficial [da República Federativa do Brasil]. Brasília, v. 03, n. 6, p.70 , 30. out. 1966, Seção. 1, PT;

BRASIL. Lei no 9.433, de 8 de janeiro de 1997. Institui a Política Nacional de Recursos Hídricos. Diário Oficial [da República Federativa do Brasil]. Brasília, v. 135, n. 6, p.40 , 18. jan. 1997, Seção. 1, pt;

DANTAS, R. A. Engenharia de Avaliações: uma Introdução à Metodologia Científica. São Paulo: Pini, 2003. 262 p.

GOMES, C.A.B de M; BAPTISTA, M.B; NASCIMENTO, N.O. Financiamento da Drenagem Urbana: Uma Reflexão. Revista Brasileira de Recursos Hídricos. Volume 13 n. 3 jul/Set 2008, 93-104;

MARCON, H., VAZ JUNIOR, S.N. Proposta de Remuneração dos Custos de Operação e Manutenção do Sistema de Drenagem do Município de Santo André - a taxa de drenagem. Anais do $20^{\circ}$. Congresso Brasileiro de Engenharia Sanitária e Ambiental, Rio de Janeiro. ABES, p. 3225-3234, 1999;

MARGULIS, S; HUGHES, G; GAMBRILL, M; AZEVEDO, L. G. T. Brasil: A Gestão da Qualidade da Água. Inserção de Temas Ambientais no setor Hídrico. Banco Mundial - Brasil, 72 p, Nov. 2002;

NBR - 12721 - "Avaliação de custos unitários e preparo de orçamento de construção para incorporação de edifícios em condomínio - Procedimento". ABNT;

PORTELA, R.S. Participação Popular e Metamorfoses no Planejamento e na Gestão do Espaço Urbano. Adcontar, Belém, v. 5, n.1. p. 15-34, junho, 2004;

SNAl, Secretaria Nacional de Assuntos Institucionais. Macrodrenagem e Urbanização do Tucunduba. Diretório Nacional do PT. Prefeitura Municipal de Belém, 2004. Disponível em <http://www.pt.org.br>. Acesso em Jan. 2009;

TRINDADE JUNIOR, Saint-Clair C. Produção do Espaço e Uso do Solo Urbano em Belém. Belém: NAEA/UFPA,1997:
TUCCI, C. E. M. Programa de drenagem sustentável: apoio ao desenvolvimento do manejo das águas pluviais urbanas - Versão 2.0. Brasília: Ministério das Cidades, 2005.

TUCCI, C.E.M. Gerenciamento da Drenagem Urbana. RBRH revista Brasileira de Recursos Hídricos, $A B R H$ - Associação Brasileira de Recursos Hídricos, Porto Alegre, v. 7, n. 1., p. 5-27, 2002;

TUCCI, C.E.M. Plano Diretor de Drenagem Urbana: Princípios e Concepção. RBRH V2 n² p. 5-612. 1997.

\section{The Billing Rate as an Alternative Funding Plan for Urban Drainage in the City of Belem/PA}

\section{ABSTRACT}

Municipal urban drainage system actions in most Brazilian cities, require significant investments. These investments come from state resources, the federal government and/or international funds, and are intended for structural and nonstructural actions to implement and maintain a drainage plan. On the other hand, these actions are encumbered by the municipal administrative apparatus, which greatly weakens preventive (nonstructural) measures and favors remedial (structural) measures. The latter are incompatible with the municipal budget, perpetuating the culture of loans. Therefore, the main purpose of this article is the assessment of a fee in an Experimental Area Billing (EAB) in Belem/PA which allows obtaining parameters to infer the feasibility of funding the urban drainage sector. The area to be analyzed is located in the Terra Firme neighborhood, in the Tucunduba basin, which in 2002 received an investment of US\$ 9.88 million in the $1^{\text {st }}$ of 3 stages of the project covering a drainage plan for macro and minor drainage. Of this amount, $73 \%$ were sourced from a loan from the FGTS and $27 \%$ financed by the municipality itself. Estimated data for the EAB included an average of 4.16 inhab/household, for an area of $48,415.74 \mathrm{~m}^{2}$, where $78.21 \%$ are occupied in a disorderly fashion and $59.24 \%$ of these occupations are areas that have become impervious; the economic characteristic of the population, with regard to income, is about 2 times the minimum wage. Thus, initially, there was the historical aspect of the drainage works in the city of Belem/PA, as well as the rationale for the Urban Master Plan and forms of financing urban drainage, which help understand the legal issues of recovery. We applied the methods of Tucci (2002) and Gomes et. al (2008) and the results were correlated with the area and frontage of the property, and family income for each residential unit, obtaining workable models according to the coefficient of determination. These models are presented as a mechanism for financing urban drain- 
age for the city of Belem/PA and can be applied to other areas according to municipal zoning.

Key-word: Urban Drainage Plan, Rate, Tucunduba basin, in Belem/PA. 